\title{
Cytotoxicity and Radiosensitization of High Grade Glioma Cells by CI-1033, an Irreversible Pan-ErbB Inhibitor
}

Dannis G van Vuurden ${ }^{1,2 *}$, Shruti Shukla ${ }^{1,2}$, Laurine E Wedekind ${ }^{1,2,3}$, Gitta K. Kuipers ${ }^{3}$, David P Noske ${ }^{2,4}$, W Peter Vandertop ${ }^{4}$, M Vincent M Lafleur $^{3}$, Ben J Slotman ${ }^{3}$, Esther Hulleman ${ }^{1,2}$, Gertjan JL Kaspers ${ }^{1}$ and Jacqueline Cloos $^{5}$

${ }^{1}$ Department of Pediatric Oncology / Hematology, VU University Medical Center, Amsterdam, The Netherlands

${ }^{2}$ Neuro-oncology Research Group, VU University Medical Center, Amsterdam, The Netherlands

${ }^{3}$ Department of Radiation Oncology, VU University Medical Center, Amsterdam, The Netherlands

${ }^{4}$ Neurosurgical Center Amsterdam, VU University Medical Center, Amsterdam, The Netherlands

${ }^{5}$ Department of Hematology, VU University Medical Center, Amsterdam, The Netherlands

\begin{abstract}
Background: High-grade gliomas (HGG) are highly infiltrative malignancies, causing considerable mortality in child- and adulthood, necessitating new therapies. Novel therapies directed against multiple epidermal growth factor family (ErbB) members are potentially effective in HGG.
\end{abstract}

Aim: To assess ErbB family expression in normal brain and pediatric and adult HGG in silico and to determine radiosensitizing properties of the pan-ErbB inhibitor $\mathrm{Cl}-1033$, in HGG cells in vitro.

Material and methods: In silico mRNA array expression analysis was performed to assess EGFR, ERBB2, $E R B B 3, E R B B 4$ gene expression in normal brain, adult and pediatric HGG. ErbB family protein expression was determined in HGG cell lines using Western blot. Sulforhodamine-B assay was used to assess cytotoxicity of Cl1033 and clonogenic assays to determine radiosensitization. The effect on cell cycle distribution and PI3K-Akt/ Ras-MAPK signalling of $\mathrm{Cl}-1033 \pm$ radiation was measured using flow cytometry.

Results: EGFR and ERBB2 were significantly overexpressed in datasets of pediatric and adult HGG. Heterogeneous protein expression of EGFR, ErbB2, 3 and 4 was observed in HGG cell lines. Cl-1033 IC50 values of $1.0 \mu \mathrm{M}, 2.5 \mu \mathrm{M}$ and $4.3 \mu \mathrm{M}$ were found in D384MG, U-251 MG and Gli-6 cells, respectively. Cl-1033 significantly sensitized Gli-6 and D384MG cells to radiation, with 24 and 48 hrs pre-treatment respectively.

Conclusion: EGFR and ErbB2 are overexpressed in adult and childhood HGG. Irreversible pan-ErbB inhibition by $\mathrm{Cl}-1033$ is cytotoxic and radiosensitizes HGG cell lines in vitro, warranting further in vivo studies.

Keywords: Receptor; Epidermal Growth Factor; CI-1033; Radiation; Glioma; Glioblastoma

\section{Introduction}

High grade gliomas (HGG), most commonly glioblastoma multiforme (GBM) and anaplastic astrocytoma (AA), are highly malignant, diffusely growing, infiltrative brain tumors in children and adults. Despite aggressive multimodality treatment strategies, prognosis is still poor in these patients, with 3-year overall survival (OS) rates of $16(+/-4) \%$ in adults, and $22(+/-5) \%$ in children $[1,2]$. New therapies are therefore warranted. In recent years, monoclonal antibodies and tyrosine kinase inhibitors (TKI), directed against the ErbB growth factor receptor family of tyrosine kinases are increasingly used as novel anti-cancer agents in multiple cancers, including HGG [3]. In adult GBM, EGFR is the most commonly amplified gene (in approximately $40 \%$ of cases) and EGFR expression has been described as an independent marker for poor prognosis [4]. The amplified EGFR gene is frequently rearranged, resulting in a constitutively activated, ligand-independent EGF receptor, EGFRvIII [5]. In childhood HGG, EGFR expression is observed in up to $58 \%$ of cases and recently EGFRvIII was detected in $4 / 9$ cases of diffuse intrinsic pontine glioma (DIPG) [6,7]. EGFR expression and pathway activation has been correlated with radioresistance, via activation of DNA-dependent protein kinase, catalytic subunit (DNA PKcs), either by direct interaction with EGFR or indirect via ErbB family mediated PI3KAkt signalling. Furthermore, Ras/MAPK pathway deregulation, either
ErbB family mediated or in crosstalk with the PI3K/Akt pathway is described to convey radioresistance $[5,8,9]$.

Considering the involvement of EGFR signalling in HGG, these tumors might benefit from enhancement of radiosensitivity by ErbB family interference. CI-1033 (Canertinib) has the distinct advantage of being a highly selective, irreversible pan-ErbB family TKI, with an additional advantage of blocking mutant EGFR variant EGFRvIII, a determinant of radioresistance in GBM cells [10]. CI-1033 has already been employed and proven to be well tolerated in multiple phase I and II studies in solid tumors, as monotherapy and in combination with cytotoxic agents [11-13]. In vitro and in vivo studies of CI-1033 as single agent or in concert with other chemo- or radiotherapeutic

*Corresponding author: Dannis G van Vuurden, MD, Department of Pediatric Oncology/ Hematology, VU University Medical Center, PO Box 7057, 1007 MB Amsterdam, the Netherlands, Tel: +31-20-444-2420; Fax: +31-20-444-2422 E-mail:dg.vanvuurden@vumc.nl

\section{Received May 07, 2013; Accepted June 09, 2013; Published June 12, 2013}

Citation: van Vuurden DG, Shukla S, Wedekind LE, Kuipers GK, Noske DP, et al. (2013) Cytotoxicity and Radiosensitization of High Grade Glioma Cells by Cl-1033, an Irreversible Pan-ErbB Inhibitor. J Cancer Sci Ther 5: 249-255. doi:10.4172/19485956.1000213

Copyright: (C) 2013 van Vuurden DG, et al. This is an open-access article distributed under the terms of the Creative Commons Attribution License, which permits unrestricted use, distribution, and reproduction in any medium, provided the original author and source are credited. 
strategies have been performed in other solid tumors [14-20], but only scarcely in HGG. In this study, we therefore study cytotoxic and radiosensitizing properties of CI-1033 on HGG cells in vitro.

\section{Material and Methods}

\section{In silico analysis}

$\mathrm{R} 2$, an online microarray analysis and visualization platform, provided by the Department of Oncogenomics of the Academic Medical Centre, Amsterdam, The Netherlands (http://r2.amc.nl), was used to obtain an overview of EGFR, ERBB2, ERBB3 and ERBB4 mRNA expression in adult and pediatric HGG. MAS5.0 normalized datasets of adult HGG ( $\mathrm{n}=153$; GSE4290) [21], childhood HGG $(n=53 ;$ GSE19578) [22] were compared to normal prefrontal cortex $(n=44 ;$ GSE13564) [23]. Datasets of anaplastic astrocytoma $(n=19$; GSE4290) and glioblastoma multiforme ( $\mathrm{n}=77$; GSE4290) [21] were also compared with normal prefrontal cortex.

\section{Cell lines and culture}

The established human adult glioma cell line D384MG is a clone derived from anaplastic astrocytoma (AA) cell line G-CCM [24], whereas U-251 MG and Gli-6 cell lines originate from GBM [25]. All cells were grown in DMEM, supplemented with $10 \%$ fetal bovine serum, $2 \mathrm{mmol} / \mathrm{l} \mathrm{L}$-glutamine, $100 \mathrm{IU} / \mathrm{ml}$ penicillin and $100 \mathrm{IU} / \mathrm{ml}$ streptomycin (all from Invitrogen NV, Breda, The Netherlands). Cells were transferred to a new $25 \mathrm{~cm}^{2}$ flask every 3-4 days and maintained in a humidified incubator at $37^{\circ} \mathrm{C}$ and $7 \% \mathrm{CO}_{2}$. All cell lines were tested to exclude Mycoplasm infection.

\section{Western Blot analysis}

Whole celllysates were prepared using RIPA lysis buffer (50 mMTris$\mathrm{HCl}$ (pH 7.5), $150 \mathrm{mMNaCl}, 1 \% \mathrm{NP} 40,0.5 \% \mathrm{Na}$-deoxycholate, $0.05 \%$ SDS) supplemented with $1 \mathrm{mM}$ pefabloc (Sigma-Aldrich, Zwijndrecht, The Netherlands). Per cell line and condition, one lysate was used to detect ErbB family proteins. Protein concentration was measured using the Bio-Rad protein assay kit (Bio-Rad, Veenendaal, The Netherlands). A total of $100 \mu \mathrm{g}$ protein was loaded per lane, separated by 7.5\% SDSPAGE and transferred to PVDF membrane (Millipore, Amsterdam, The Netherlands). Subsequently the membrane was blocked with TBST (Tris buffered saline with $0.1 \%$ Tween 20 ) $+5 \%$ non-fat milk for $1 \mathrm{~h}$ at room temperature (RT) and incubated with 1:1000 mouse anti-EGFR (sc-03, Santa Cruz), ErbB2 (sc-284, Santa Cruz), ErbB3 (sc-285, Santa Cruz) or ErbB4 (sc-283, Santa Cruz) and $\beta$-actine monoclonal antibody (A5441, Sigma-Aldrich) overnight at $4^{\circ} \mathrm{C}$. Protein lysates from cell lines A431, HT-29, Hep-G2 and MCF-7 were used as positive controls for immunoblots of EGFR, ErbB2, ErbB3 and ErbB4 respectively.

The blot was washed three times with TBST $+0.5 \%$ milk and the membrane was incubated with 1:1000 goat-anti-mouse-HRP antibody (DAKO Cytomation, Glostrup, Denmark) for one hour at RT. Subsequently, the membrane was washed three times with TBST $+0.5 \%$ milk and EGFR, ErbB2, ErbB3, or ErbB4 protein and $\beta$-actin was visualized on a hyperfilm using an ECL plus system (Amersham Bioscience, England).

\section{CI-1033}

The pan-ErbB inhibitor CI-1033 (Pfizer, New York, NY, USA) was dissolved in 100\% DMSO (Sigma-Aldrich Chemie, Zwijndrecht, The Netherlands) and the stock solution of $20 \mathrm{mM}$ was stored at $-20^{\circ} \mathrm{C}$. For experiments, CI-1033 was diluted in phosphate buffered solution (PBS, Invitrogen NV, Breda, The Netherlands).

\section{Proliferation assays}

Sulforhodamine B (SRB) cell proliferation assay was used to measure CI-1033 drug sensitivity. U-251 MG, D384MG and Gli6 cells were plated at a concentration of 2,000 cells/well, 3,000 cells/ well and 4,000 cells/well $(100 \mu \mathrm{l})$, respectively, in 96 wells plates and allowed to attach for $24 \mathrm{hrs}$. Subsequently, cells were exposed for 24, 48 or $72 \mathrm{hrs}$ to CI-1033 $(0-9 \mu \mathrm{M})$ or vehicle (DMSO $0.045 \%)$. Per concentration, six wells were used. Following treatment, cells were washed, fixed with $30 \%$ trichloroacetic acid (TCA), stained with SRB and washed with $1 \%$ acetic acid. SRB stain was eluted with unbuffered Tris base (trishydroxymethyl-aminomethane) (10 mM, pH 10.5) and plates were measured at $540 \mathrm{~nm}$ using a spectrophotometer. Triplicate experiments were performed for each cell line.

\section{Clonogenic assay}

Clonogenic assay was performed as described by Franken et al. [26] In brief, D384MG, U-251 MG and Gli-6 cells were placed in a culture flask and after $24 \mathrm{hrs}$ the subconfluently growing cells were exposed to different concentrations of CI-1033 or vehicle $(0,04 \%$ DMSO) for 24 or $48 \mathrm{hrs}$ and irradiated with single doses of gamma-radiation (0-6 Gy) using a ${ }^{60}$ Cobalt source (Gammacell 200, Atomic Energy of Canada Ltd). After treatment, cells were plated in 6-wells plates in medium without CI-1033 or vehicle and incubated for 10 to 14 days to form colonies. Colonies were fixed with $10 \%$ formaldehyde (Sigma-Aldrich Chemie) and stained with 10\% Giemsa solution (Merck, Germany). Clones of more than 50 cells were scored with a microscope. Surviving fractions (SF) were calculated by dividing the plating efficiency (PE) of the CI-1033 treated cells by the PE of the vehicle-treated cells. SF for each radiation dose was corrected for the toxicity of CI-1033 alone.

\section{Intracellular immunostaining and flow cytometric analysis}

For cell cycle analysis, FACS samples were prepared following 24 or 48 hrs treatment with CI-1033 or vehicle (DMSO). Cells were collected, washed twice in PBS containing $0.1 \%$ bovine serum albumin (InvitrogenNV, The Netherlands), centrifuged at $1000 \mathrm{rpm}$ and fixed in $70 \%$ ethanol. Cells were washed twice with ice-cold PBS, incubated with $50 \mu \mathrm{g}$ RNaseA (Sigma-Aldrich, The Netherlands) for $20 \mathrm{~min}$ at RT followed by a 30 minute incubation with $50 \mu \mathrm{g}$ propidium iodide (PI, Sigma-Aldrich, The Netherlands) in the dark on ice.

For the analysis of Akt and ERK phosphorylation after 24 or $48 \mathrm{hrs}$ of treatment with CI-1033 or vehicle (DMSO), cells were fixed with $4 \%$ formaldehyde during $10 \mathrm{~min}$ at $37^{\circ} \mathrm{C}$ and put on ice for one minute. Subsequently, cells were washed twice with PBS and the cell pellet was incubated with $10 \mu \mathrm{l}$ human IgG for five min at RT, followed by 100 $\mu \mathrm{l} 0.1 \%$ saponine/PBS for five min at RT for cell permeabilization. Cells were then incubated with primary rabbit anti-human antibodies; 1:100 phospho-Akt (\#4058, Cell Signaling Technology, Danvers, MA, USA), 1:50 Akt (\#9272, Cell Signaling Technology), 1:50 phosphoERK (\#4377, Cell Signaling Technology) or 1:25 ERK (\#9102, Cell Signaling Technology) for two hrs at RT in the dark and washed four times with PBS. Next, cells were incubated at RT for $30 \mathrm{~min}$ in 100 $\mu \mathrm{l} 0.1 \%$ saponine/PBS and 1:200 goat-anti-rabbit-biotine and washed twice with PBS, incubated with $100 \mu \mathrm{l} 0.1 \%$ saponine/PBS and 1:20 streptavidin PE for $15 \mathrm{~min}$ at RT in the dark and washed four times with PBS. Finally, $200 \mu 10.5 \%$ paraformaldehyde was added.

Cells were then analyzed by a Becton Dickinson FACS scanner and the data were analyzed by ModFit LT (Verity Software House, USA). 

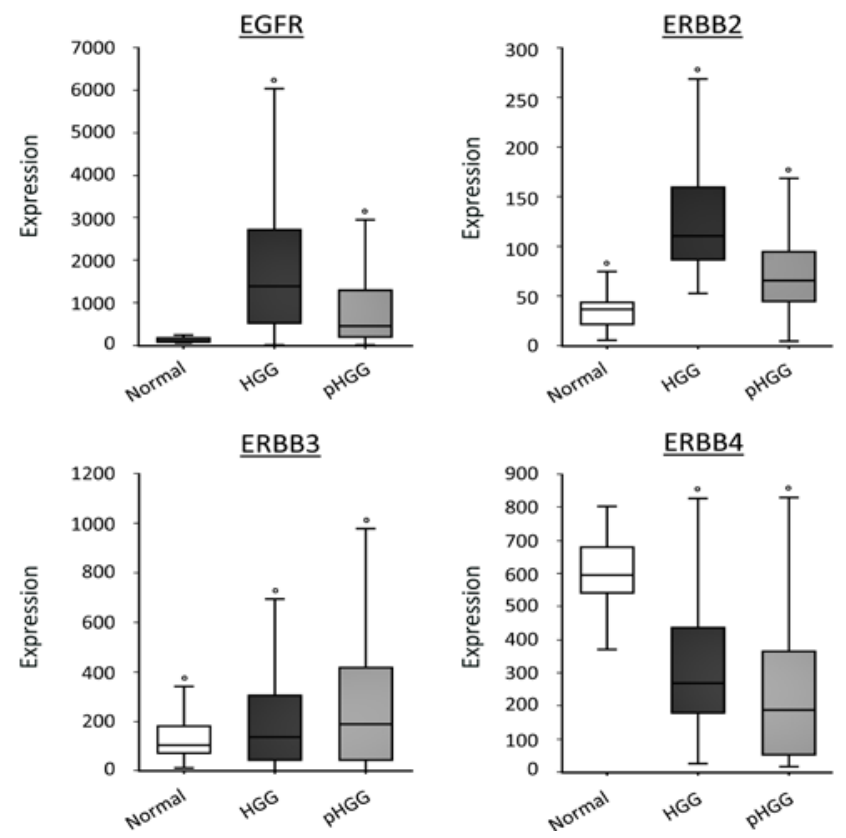

Figure 1: In silico analysis of EGFR, ERBB2, ERBB3 and ERBB4 mRNA expression using R2 analysis software on datasets of non-malignant brain tissues of cerebral cortex (white, $n=44$ ) versus datasets of adult (dark grey, $\mathrm{n}=153$ ) and pediatric HGG (grey, $n=53$ ). Y-axis shows expression in arbitrary units. Boxplots represent $25 \%, 50 \%$ (median), and $75 \%$ values, with error bars indicating maximum and minimum values for each category. Statistical outliers are indicated by small circles.

Pre-G1 peak analysis of the PI FACS measurements was used to assess apoptosis in the samples.

\section{Statistics}

For the in silico analysis of ERBB family members in adult and pediatric HGG, one-sided analysis of variance (ANOVA) was used to compare EGFR, ERBB2, ERBB3 and ERBB4 mRNA expression between the dataset of normal brain tissue and each dataset of adult and pediatric HGG. A $p$-value $<0.0005$ was considered statistically significant. Analysis of inhibitory concentrations in the SRB proliferation assay was performed using SigmaPlot 11.0 (Systat Software, Inc. San Jose, CA, USA), in which the IC50s were calculated with a four parameter logistic equation. For clonogenic cell survival, curves were constructed by nonlinear regression according to the linear-quadratic formula using GraphPad Prism software (GraphPad Software Inc., USA). Differences between survival curves were analyzed using Statistical Package for Social Sciences (SPSS, Chicago, IL, USA) statistical software, as previously described [26]. Dose modifying factors at a survival fraction of 0.2 were calculated to quantify radiosensitization, as described by Franken et al. [26].

\section{Results}

EGFR and ERBB2 mRNA overexpression in adult and pediatric HGG

ErbB family (EGFR, ERBB2, ERBB3 and ERBB4) mRNA expression was determined in two datasets of HGG (adult and pediatric HGG) and non-malignant brain tissues (Figure 1). EGFR and ERBB2 were significantly overexpressed in both datasets of glioma, as compared to normal brain. ERBB4 was significantly downregulated in adult and pediatric HGG, as compared to normal cortex. Moreover, additional in silico analysis showed EGFR and ERBB2 to be overexpressed in anaplastic astrocytoma and to higher extent in glioblastoma multiforme (Supplementary figure S2).

\section{High grade glioma cell lines are differentially sensitive to pan-ErbB inhibition by CI-1033}

Western Blot was used to analyse EGFR, ErbB2, ErbB3 and ErB4 protein expression in U-251 MG, D384MG and Gli-6 HGG cells. In all cell lines moderate/strong EGFR $(170 \mathrm{kD})$ and weak/moderate ErbB4 $(185 \mathrm{kD})$ protein expression was detected. ErbB2 $(185 \mathrm{kD})$ was strongly
A

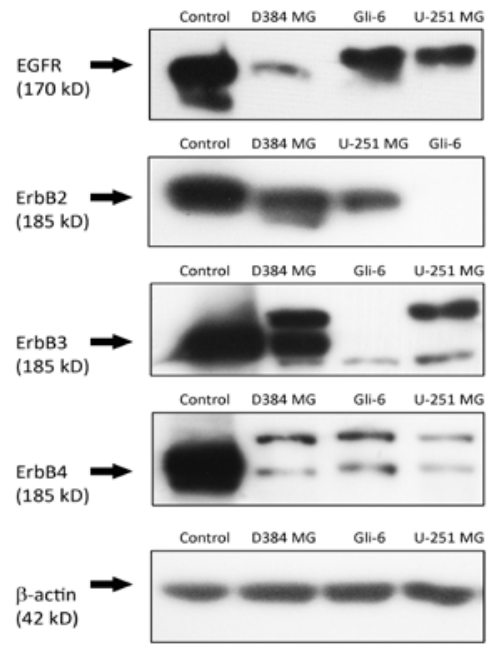

B

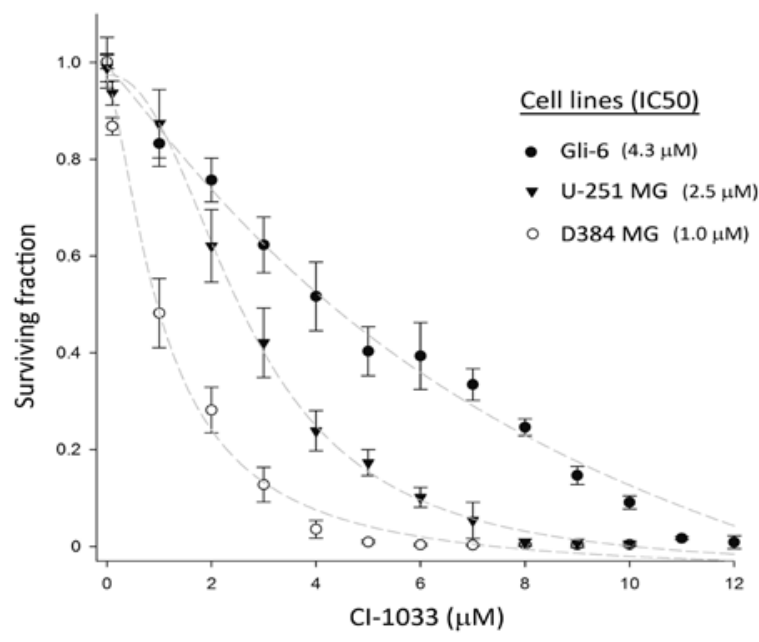

Figure 2: (A) Immunoblot of baseline EGFR (170 kD), ErbB2 (185 kD), ErbB3 (185kD), ErbB4 (185kD) expression in HGG cell lines and control cell lines (A431, HT-29, Hep-G2, MCF-7 cells respectively). Representative beta actin staining from the ErbB3 immunoblot (42 kD). (B) Cell viability assay for HGG cell lines, exposed to the indicated concentrations of $\mathrm{Cl}-1033$ (Canertinib). Cell viability was assayed after $72 \mathrm{hrs}$ exposure. Dots indicate mean values of experiments performed in triplicate. Bars indicate standard deviation of the mean (SD). $\mathrm{IC}_{50}$ values are calculated using Sigma Plot and are indicated between brackets. 
expressed in U-251 MG and D384MG cells, no ErbB2 was detected in Gli-6 cells. ErbB3 $(185 \mathrm{kD})$ was found only in D384MG cells (Figure $2 \mathrm{~A})$.

To determine the effect of ErbB family inhibition on cell proliferation, we first exposed the cells to pan-ErbB inhibitor CI-1033 as a single agent. In figure 3 the effect of CI-1033 treatment on glioma cell lines Gli-6, U-251 MG and D384MG is shown. The AA cell line D384MG showed high sensitivity to CI-1033 treatment as compared to the other cell lines, with a $50 \%$ inhibitory concentration (IC50) of 1.0 $\mu \mathrm{M}$. GBM cell lines U-251 MG and Gli-6 were observed to be less sensitive, with IC50 values of $2.5 \mu \mathrm{M}$ and $4.3 \mu \mathrm{M}$ respectively (Figure 2B).

\section{Differential effects of CI-1033 on cell cycle kinetics in HGG cells}

Cell cycle analysis after 24 and 48 hrs was performed on HGG cell lines Gli-6, D384MG and U-251 MG after treatment with vehicle or 8 $\mu \mathrm{M}, 5 \mu \mathrm{M}$ and $8 \mu \mathrm{M}$ CI-1033 respectively. With these concentrations, growth was almost completely inhibited (Figure 3A). In U-251 MG and Gli- 6 cells an increase of G2/M cell cycle arrest at 24 and $48 \mathrm{hrs}$
CI-1033 treatment was observed, which was partly resolved at $48 \mathrm{hrs}$ in U-251 MG cells (Figure 3B and C). In D384MG cells no apparent effects on cell cycle were detected (Figure 3D). However, analysis of sub-G1 populations, showed increased apoptosis in this cell line (up to $35 \%$ ), contrary to U-251 MG and Gli-6 in which $\pm 6 \%$ apoptotic cells were detected (data not shown).

Pan-ErbB inhibition with CI-1033 differentially sensitizes HGG cells to radiation, dependent on preincubation period

To investigate whether irreversible inhibition of ErbB family members enhances radiosensitivity by decreased clonogenic capacity, clonogenic assays were performed in HGG cell lines. Significant enhancement of radiosensitivity upon pretreatment with CI-1033 was observed in Gli-6 and D384MG cells $(\mathrm{p}<0.001)$ (Figure 4). Interestingly, Gli- 6 cells showed enhanced radiation sensitivity upon $24 \mathrm{hrs}$ pre-incubation with CI-1033 and not with $48 \mathrm{hrs}$ pre-treatment, whereas in D384MG cells the opposite was observed: only $48 \mathrm{hrs}$ pretreatment resulted in significant radiosensitization. U-251 MG did not show increased radiosensitivity with CI-1033 treatment in either preincubation schedule.
A

Gli-6

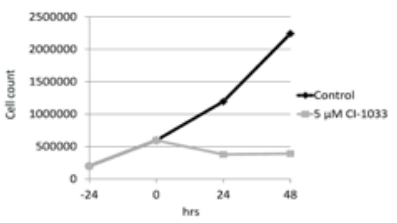

U251-MG

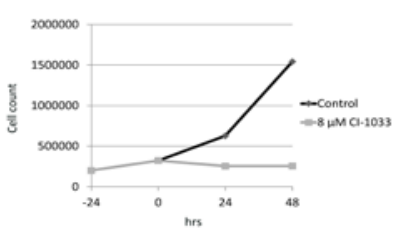

C
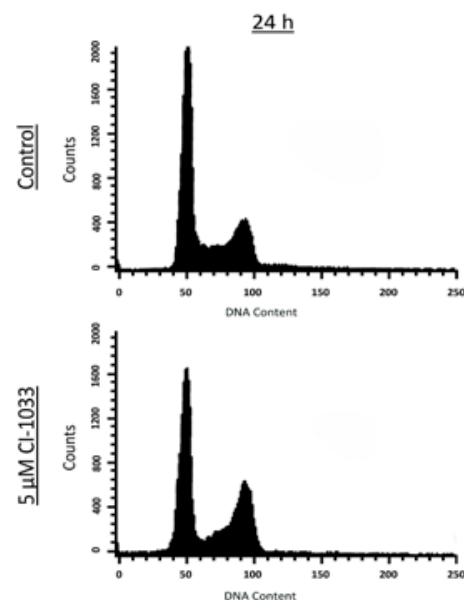

D384-MG
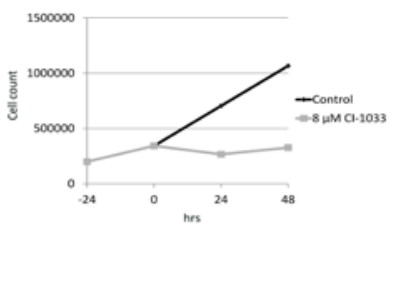

B
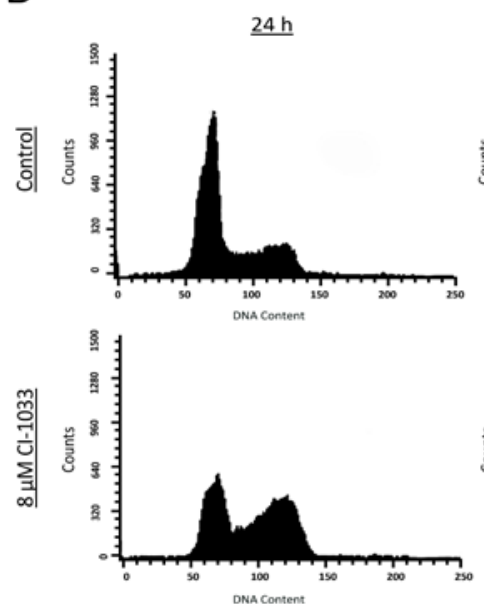

D

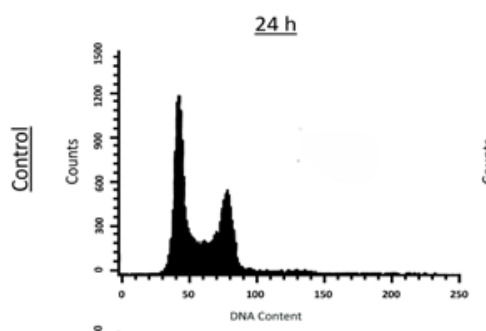

U251-MG
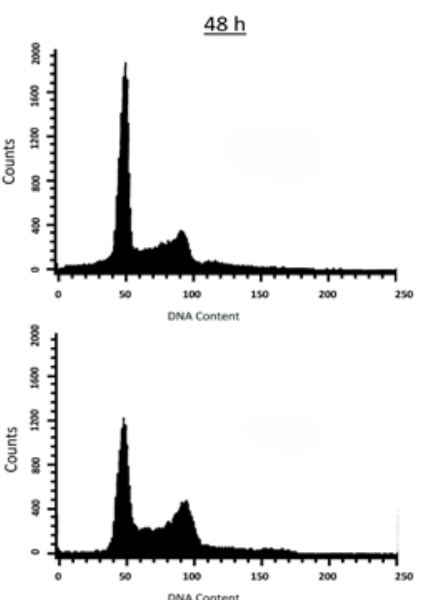
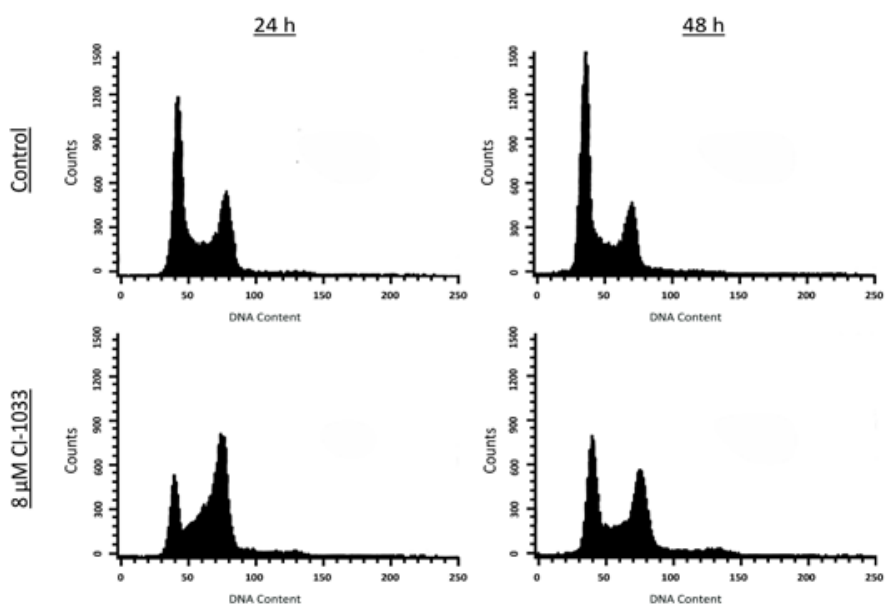

Figure 3: Cell cycle profiles of Gli-6, D384MG and U-251 MG HGG cells treated with either control (DMSO) or $5 \mu \mathrm{M}, 8 \mu \mathrm{M}$ and $8 \mu \mathrm{M}$ Cl-1033 respectively. (A) Growth inhibition with $\mathrm{Cl}-1033$ treatment in proliferation assay. (B-D) Cell cycle distribution of cells after 24 or 48 hrs treatment with control (DMSO) or Cl-1033. 
A

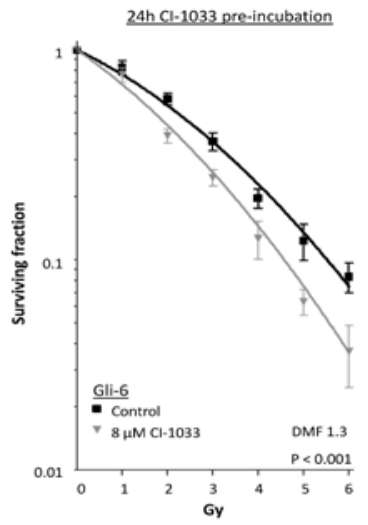

B

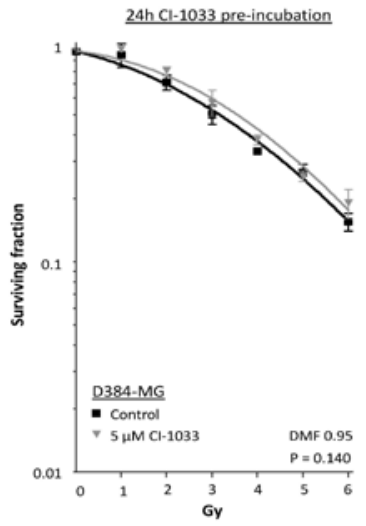

C

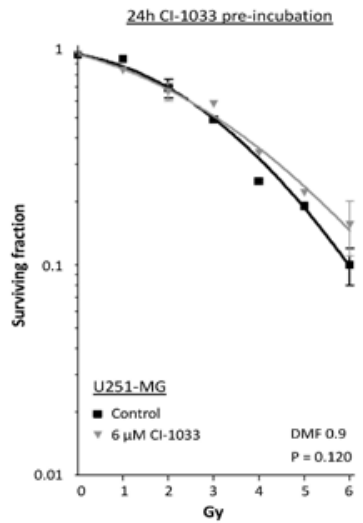

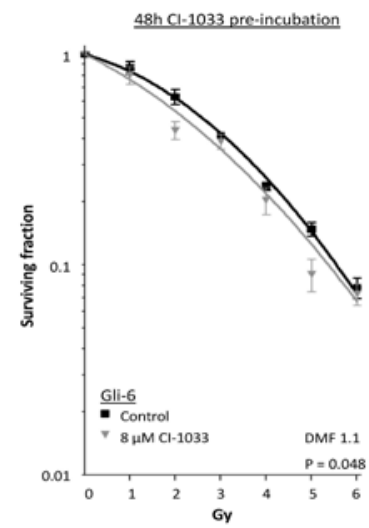
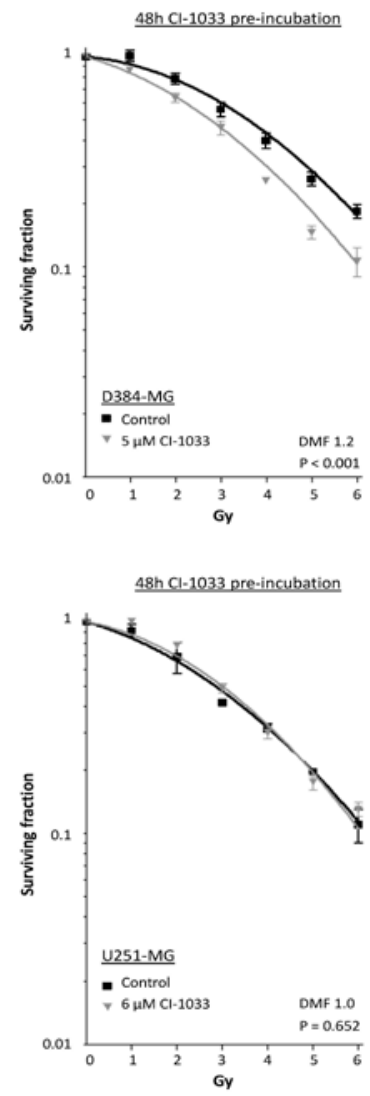

Figure 4: Clonogenic survival curves after 24 hrs (left) or 48 hrs (right) preincubation with $\mathrm{Cl}-1033$ before radiation (RT). Dose modifying factors (DMF) at a surviving fraction of 0.2 were determined for each cell line for $24 \mathrm{hr}$ and $48 \mathrm{hr}$ : (A), 1.3 and 1.1 respectively for Gli-6, (B) 0.95 and 1.2 respectively for D384MG, (B) 0.9 and 1.0 for U-251 MG: (C). In all experiments DMSO was used as a control. Error bars show the mean \pm SD of at least two independent experiments. $P$ values $<0.05$ indicate statistically significant differences between radiation alone and radiation combined with $\mathrm{Cl}-1033$.

\section{ErbB family members in HGG cells downregulated after} treatment with CI-1033

To investigate the effect of CI-1033 and radiotherapy on ErbB family members protein expression, HGG cell lines U-251 MG, D384MG and Gli-6, were treated with $8 \mu \mathrm{M}, 8 \mu \mathrm{M}$ and $5 \mu \mathrm{M}$ CI-1033, respectively and/or radiation. Subsequently, EGFR, ErbB2, ErbB3 and ErbB4 were

detected by Western Blot. In all cell lines, CI-1033 treatment resulted in a strong downregulation of ErbB2, irrespective of radiotherapy (Figure 5). This phenomenon was also observed for EGFR, albeit to a lesser extent. ErbB4 was strongly reduced by CI-1033 in D384MG cells, and slightly in U-251 MG, where baseline expression was already weak. Upon radiation alone,U-251 MG cells only showed weak upregulation of ErbB3, which was more pronouncedly observed in D384MG cells, that also showed moderate EGFR upregulation, whereas CI-1033 efficiently reduced radiation induced upregulation.

\section{Akt and ERK pathway inhibition in HGG cells upon treatment with CI-1033}

To ascertain downstream effects of irreversible ErbB family tyrosine kinase domain blockage by CI-1033 and radiation in HGG cells, levels of phosphorylated Akt, total Akt, phosphorylated ERK and total ERK were measured by FACS. To this purpose, U-251 MG, D384MG and Gli- 6 cells were incubated with either CI-1033 or vehicle for $24 \mathrm{hrs}$, and irradiated with $4 \mathrm{~Gy}$ or not irradiated. Compared to vehicle control, treatment with CI-1033 resulted in a marked reduction of absolute Akt and ERK phosphorylation in both Gli-6 and D384MG cells, which was sustained after radiation (Supplementary figure S1). Interestingly, U-251 MG cells, that did not show a radiosensitizing effect with CI-1033 pre-treatment, did not reveal diminished Akt and ERK phosphorylation: even a mild to moderate increase was observed.

\section{Discussion}

ErbB family signalling involves highly complex signal transduction cascades between multiple inter-related pathways. Heterogeneity at the cellular and molecular level and redundant or overlapping signalling between these pathways may explain, in part, the therapeutic resistance of HGG to agents directed against single ErbB family members. Indeed, inhibiting a specific ErbB member and pathway may result in activation of compensatory receptors and pathways, allowing glioma cell survival [27]. Thus, an irreversible, pan-ErbB inhibitor is to be expected to exceed the efficacy of single ErbB family TKI or monoclonal antibodies, overcoming and preventing (mutation-related) resistance to these agents in HGG [28].

In our study, we performed in silico analysis of the ErbB family members in mRNA datasets of adult and childhood HGG, which revealed that $E G F R$ and ERBB2 were significantly overexpressed to normal brain in all datasets. ERBB4 however, was markedly downregulated compared to normal brain tissue. Furthermore, increasing expression of both EGFR and ERBB2 was observed with increasing grade of malignancy in AA and GBM respectively, suggesting a role in malignant transformation (Supplementary figure S2). These profiles of overexpression suggest that targeting more than one ErbB family member might be of therapeutic benefit in both AA and GBM. Analogous to the in silico analysis, EGFR and ErbB2 were expressed in all three HGG cell lines tested, but ErbB3 only in AA cell line D384MG. Moderate expression of the ErbB4 receptor was observed in all three cell lines.

Irreversible pan-ErbB family tyrosine kinase inhibition by CI-1033 resulted in differential and potent growth inhibition in the HGG cell lines tested, with IC50 values ranging from $1-4.3 \mu \mathrm{M}$, which is within the range of in vitro studies in other cancer cell lines [29]. Interestingly, AA cell line D384MG, harbouring all four ErbB family members, showed the highest sensitivity to CI-1033, whereas the higher sensitivity of U-251 MG compared to Gli-6 might be explained by the expression of ErbB2 in the former. The paradigm of ErbB family member expression 

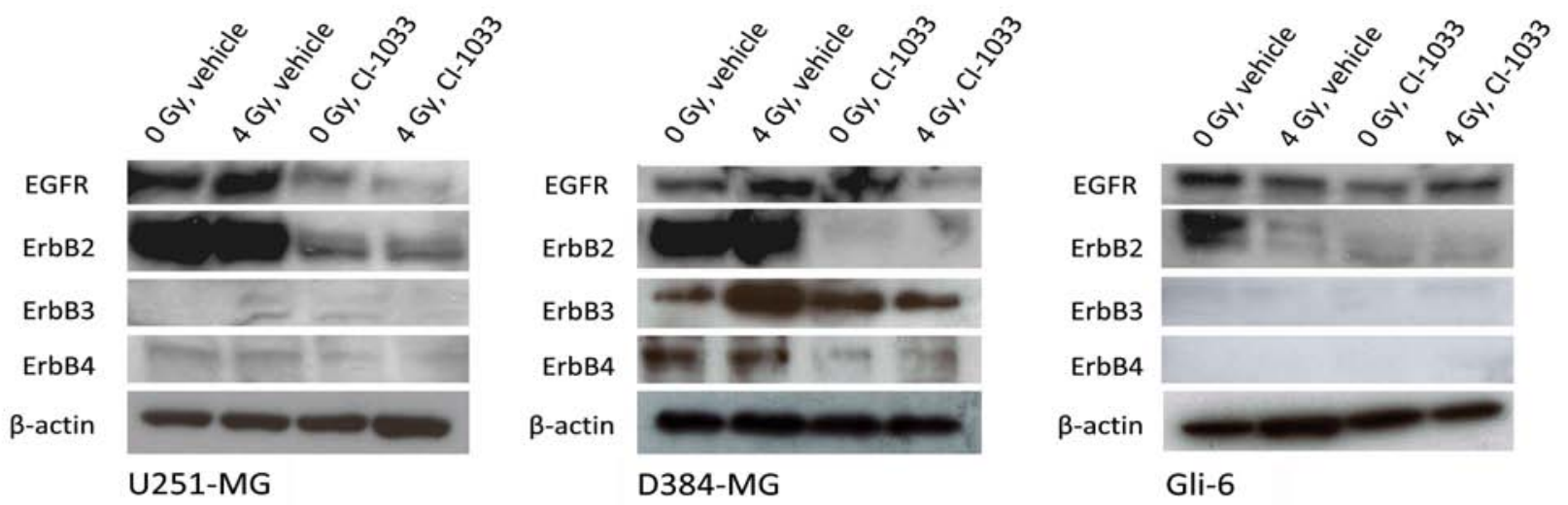

Figure 5: Immunoblot of EGFR, ErbB2, ErbB3 and ErbB4 expression in HGG cells after 24 hrs of treatment with $\mathrm{Cl}-1033$ or vehicle, with or without 4 Gy of irradiation. Gli-6 cells were pretreated with $5 \mu \mathrm{M} \mathrm{Cl}-1033, \mathrm{U}-251 \mathrm{MG}$ and D384 $\mu \mathrm{MG}$ cells with $8 \mu \mathrm{M} \mathrm{Cl}-1033$.

and sensitivity to ErbB inhibition was previously observed in lung and breast cancer [30,31]. Cell cycle arrest was observed in U-251 MG and Gli-6, whereas apoptosis contributed to the observed drug sensitivity in D384MG cells. This might be explained by both ErbB family addiction of this cell line, and a strong reduction of Akt pathway signalling upon ErbB family inhibition, abrogating apoptosis inhibition by Akt [32,33]. Upon CI-1033 treatment, strong ErbB2 downregulation was observed in all cell lines and EGFR downregulation in two out of three. This inhibitor-mediated downregulation is likely to be caused by receptor internalization, ubiquitination, and degradation [34].

This study is the first to show both potent cytotoxic effects and radiosensitization in HGG cells by pan-ErbB family inhibitor CI1033, and its modulation of EGFR downstream signalling components in these cells. Two out of three HGG cell lines could be sensitized to radiation by CI-1033 pretreatment. These results are in concordance with previously published in vitro studies showing radiosensitization in other tumor types [14-16]. Interestingly, we found these radiosensitizing effects to be schedule dependent. No differences in cell cycle distribution were found to account for this observed phenomenon. Baseline ErbB family expression could not predict the differences in radiosensitization observed, although in U-251 MG cells a less profound ErbB2 downregulation upon CI-1033 treatment might partly explain the lack of radiosensitization.

Our study is the first to show CI-1033 induced alterations of phosphorylation of EGFR family members in HGG cells. We found reduced levels of pAkt and pERK upon treatment with CI-1033, both as single agent and in concert with radiation in HGG cell lines D384MG and Gli-6. Interestingly, in these cells CI-1033 induced radiosensitization was observed. This suggests that irreversible ErbB family inhibition disrupts PI3K/Akt- and Ras/MAPK pathway signalling, leading to a diminished DNA repair response, and hereby enhancing radio sensitivity in these cells. In line with this, U-251 MG cells, in which no radiosensitization was observed, showed strong upregulation phosphorylated Akt and to a lesser extent upregulation of phospho-ERK after CI-1033 treatment. Interestingly, the U-251 MG cell line harbors a homozygous inactivating PTEN mutation (723_724insTT; E242fs ${ }^{*}$ ) [35] which might explain this observed Akt activation and lack of radiosensitization, due to increased Akt activity. Activation of both Akt and EGFR as a result of loss of PTEN was described earlier in EGFR inhibitor resistance in GBM and non small-cell lung cancer [36,37].

In conclusion, our study is one of the first to show CI-1033 induced cytotoxicity and radiosensitization in glioma cell lines in vitro. This warrants further in vivo orthotopic GBM mice studies, studying timing of the combination of CI-1033 with RT ( \pm temozolomide). More research is needed to define predictors of CI-1033 induced radiosensitization. Ultimately, CI-1033 might be an interesting drug to study in clinical studies in adults and children with HGG, aiming to improve the dismal prognosis of these cancers.

\section{Acknowledgements}

We thank Dr. T. Würdinger for critically reading this manuscript.

\section{Funding}

This work was supported by VUmc Cancer Center Amsterdam (VUmc-CCA) $\mathrm{EH}$ is supported by Stichting Semmy.

\section{Ethical Standards}

The experiments comply with the current laws of the Netherlands.

\section{Conflict of Interest}

The authors declare that they have no conflict of interest.

\section{References}

1. Cohen KJ, Pollack IF, Zhou T, Buxton A, Holmes EJ, et al. (2011) Temozolomide in the treatment of high-grade gliomas in children: a report from the Children's Oncology Group. Neuro Oncol 13: 317-323.

2. Stupp R, Hegi ME, Mason WP, van den Bent MJ, Taphoorn MJ, et al. (2009) Effects of radiotherapy with concomitant and adjuvant temozolomide versus radiotherapy alone on survival in glioblastoma in a randomised phase III study: 5-year analysis of the EORTC-NCIC trial. Lancet Oncol 10: 459-466.

3. De Witt Hamer PC (2010) Small molecule kinase inhibitors in glioblastoma: a systematic review of clinical studies. Neuro Oncol 12: 304-316.

4. Murat A, Migliavacca E, Gorlia T, Lambiv WL, Shay T, et al. (2008) Stem cellrelated "self-renewal" signature and high epidermal growth factor receptor expression associated with resistance to concomitant chemoradiotherapy in glioblastoma. J Clin Oncol 26: 3015-3024.

5. Hatanpaa KJ, Burma S, Zhao D, Habib AA (2010) Epidermal growth factor receptor in glioma: signal transduction, neuropathology, imaging, and radioresistance. Neoplasia 12: 675-684.

6. Liang ML, Ma J, Ho M, Solomon L, Bouffet E, et al. (2008) Tyrosine kinase expression in pediatric high grade astrocytoma. J Neurooncol 87: 247-253. 
Citation: van Vuurden DG, Shukla S, Wedekind LE, Kuipers GK, Noske DP, et al. (2013) Cytotoxicity and Radiosensitization of High Grade Glioma Cells by Cl-1033, an Irreversible Pan-ErbB Inhibitor. J Cancer Sci Ther 5: 249-255. doi:10.4172/1948-5956.1000213

7. Li G, Mitra SS, Monje M, Henrich KN, Bangs CD, et al. (2012) Expression of epidermal growth factor variant III (EGFRvIII) in pediatric diffuse intrinsic pontine gliomas. J Neurooncol 108: 395-402.

8. Nyati MK, Morgan MA, Feng FY, Lawrence TS (2006) Integration of EGFR inhibitors with radiochemotherapy. Nat Rev Cancer 6: 876-885.

9. Toulany M, Rodemann HP (2010) Membrane receptor signaling and control of DNA repair after exposure to ionizing radiation. Nuklearmedizin 49 Suppl 1: S26-30.

10. Mukherjee B, McEllin B, Camacho CV, Tomimatsu N, Sirasanagandala S, et al. (2009) EGFRvIII and DNA double-strand break repair: a molecular mechanism for radioresistance in glioblastoma. Cancer Res 69: 4252-4259.

11. Jänne PA, von Pawel J, Cohen RB, Crino L, Butts CA, et al. (2007) Multicenter, randomized, phase II trial of $\mathrm{Cl}-1033$, an irreversible pan-ERBB inhibitor, for previously treated advanced non small-cell lung cancer. J Clin Oncol 25: 3936 3944.

12. Rixe O, Franco SX, Yardley DA, Johnston SR, Martin M, et al. (2009) A randomized, phase II, dose-finding study of the pan-ErbB receptor tyrosinekinase inhibitor $\mathrm{Cl}-1033$ in patients with pretreated metastatic breast cancer. Cancer Chemother Pharmacol 64: 1139-1148.

13. Zinner RG, Nemunaitis J, Eiseman I, Shin HJ, Olson SC, et al. (2007) Phase I clinical and pharmacodynamic evaluation of oral $\mathrm{Cl}-1033$ in patients with refractory cancer. Clin Cancer Res 13: 3006-3014.

14. Murakami M, Sasaki T, Yamasaki S, Kuwahara K, Miyata H, et al. (2004) Induction of apoptosis by ionizing radiation and $\mathrm{Cl}-1033$ in HuCCT-1 cells. Biochem Biophys Res Commun 319: 114-119.

15. Nyati MK, Maheshwari D, Hanasoge S, Sreekumar A, Rynkiewicz SD, et al. (2004) Radiosensitization by pan ErbB inhibitor $\mathrm{Cl}-1033$ in vitro and in vivo. Clin Cancer Res 10: 691-700.

16. Rao GS, Murray S, Ethier SP (2000) Radiosensitization of human breas cancer cells by a novel ErbB family receptor tyrosine kinase inhibitor. Int J Radiat Oncol Biol Phys 48: 1519-1528.

17. Slichenmyer WJ, Elliott WL, Fry DW (2001) Cl-1033, a pan-erbB tyrosine kinase inhibitor. Semin Oncol 28: 80-85.

18. Skvortsov S, Skvortsova I, Sarg B, Loeffler-Ragg J, Lindner H, et al. (2005) Irreversible pan-ErbB tyrosine kinase inhibitor $\mathrm{Cl}-1033$ induces caspaseindependent apoptosis in colorectal cancer DiFi cell line. Apoptosis 10: 11751186.

19. Hughes DP, Thomas DG, Giordano TJ, McDonagh KT, Baker LH (2006) Essential erbB family phosphorylation in osteosarcoma as a target for $\mathrm{Cl}-1033$ inhibition. Pediatr Blood Cancer 46: 614-623.

20. Ako E, Yamashita Y, Ohira M, Yamazaki M, Hori T, et al. (2007) The pan-erbB tyrosine kinase inhibitor $\mathrm{Cl}-1033$ inhibits human esophageal cancer cells in vitro and in vivo. Oncol Rep 17: 887-893.

21. Sun L, Hui AM, Su Q, Vortmeyer A, Kotliarov Y, et al. (2006) Neuronal and glioma-derived stem cell factor induces angiogenesis within the brain. Cancer Cell 9: 287-300.

22. Paugh BS, Qu C, Jones C, Liu Z, Adamowicz-Brice M, et al. (2010) Integrated molecular genetic profiling of pediatric high-grade gliomas reveals key differences with the adult disease. J Clin Oncol 28: 3061-3068.

23. Harris LW, Lockstone HE, Khaitovich P, Weickert CS, Webster MJ, et al. (2009) Gene expression in the prefrontal cortex during adolescence: implications for the onset of schizophrenia. BMC Med Genomics 2: 28.

24. Balmforth AJ, Ball SG, Freshney RI, Graham DI, McNamee HB, et al. (1986) $\mathrm{D}-1$ dopaminergic and beta-adrenergic stimulation of adenylate cyclase in a clone derived from the human astrocytoma cell line G-CCM. J Neurochem 47: 715-719.

25. Pontén J, Macintyre EH (1968) Long term culture of normal and neoplastic human glia. Acta Pathol Microbiol Scand 74: 465-486.
26. Franken NA, Rodermond HM, Stap J, Haveman J, van Bree C (2006) Clonogenic assay of cells in vitro. Nat Protoc 1: 2315-2319.

27. Clark PA, lida M, Treisman DM, Kalluri H, Ezhilan S, et al. (2012) Activation of multiple ERBB family receptors mediates glioblastoma cancer stem-like cell resistance to EGFR-targeted inhibition. Neoplasia 14: 420-428.

28. Belani CP (2010) The role of irreversible EGFR inhibitors in the treatment of non-small cell lung cancer: overcoming resistance to reversible EGFR inhibitors. Cancer Invest 28: 413-423.

29. Djerf Severinsson EA, Trinks C, Gréen H, Abdiu A, Hallbeck AL, et al. (2011) The pan-ErbB receptor tyrosine kinase inhibitor canertinib promotes apoptosis of malignant melanoma in vitro and displays anti-tumor activity in vivo. Biochem Biophys Res Commun 414: 563-568.

30. Cappuzzo F, Varella-Garcia M, Shigematsu H, Domenichini I, Bartolini S, et al. (2005) Increased HER2 gene copy number is associated with response to gefitinib therapy in epidermal growth factor receptor-positive non-small-cel lung cancer patients. J Clin Oncol 23: 5007-5018.

31. Esteva FJ, Yu D, Hung MC, Hortobagyi GN (2010) Molecular predictors of response to trastuzumab and lapatinib in breast cancer. Nat Rev Clin Oncol 7: $98-107$

32. McDowell KA, Riggins GJ, Gallia GL (2011) Targeting the AKT pathway in glioblastoma. Curr Pharm Des 17: 2411-2420.

33. Martelli AM, Tabellini G, Bressanin D, Ognibene A, Goto K, et al. (2012) The emerging multiple roles of nuclear Akt. Biochim Biophys Acta 1823: 2168-2178.

34. Suzuki T, Fujii A, Ochi H, Nakamura H (2011) Ubiquitination and downregulation of ErbB2 and estrogen receptor-alpha by kinase inhibitor MP-412 in human breast cancer cells. J Cell Biochem 112: 2279-2286.

35. Bleeker FE (2009) Mutational profiling of glioblastoma. Thesis; Faculty of Medicine: University of Amsterdam), pp. 176.

36. Sos ML, Koker M, Weir BA, Heynck S, Rabinovsky R, et al. (2009) PTEN loss contributes to erlotinib resistance in EGFR-mutant lung cancer by activation of Akt and EGFR. Cancer Res 69: 3256-3261.

37. Fenton TR, Nathanson D, Ponte de Albuquerque C, Kuga D, Iwanami A, et al. (2012) Resistance to EGF receptor inhibitors in glioblastoma mediated by phosphorylation of the PTEN tumor suppressor at tyrosine 240. Proc Natl Acad Sci U S A 109: 14164-14169. 